\title{
MINERAÇÃO DE ÁGUA MINERAL: QUALIDADE PARA O CONSUMO HUMANO E PROMOÇÃO DE SAÚDE
}

\author{
Antônio José Ribeiro Nunes ${ }^{1}$
}

RESUMO: O presente estudo avalia os aspectos da pesquisa e lavra na mineração de água mineral subterrânea e tem como objetivo analisar o controle da qualidade da água mineral e sua importância para o consumo humano e promoção de saúde. Pretendeu-se demonstrar as diretrizes do Código de Mineração e Código de Águas como balizadores legais sob gestão da Agência Nacional de Mineração - ANM, ente federal regulador da exploração de águas minerais; analisar a importância do controle da qualidade da água para o consumo humano, a partir do atendimento às Resoluções Anvisa - RDC-274/275/2005, que normatizam o envase e características microbiológicas. Conhecer esses aspectos possibilitou fazer reflexões que subsidiem a escolha e questionamentos. Portanto, considerando a importância da água para o ser humano, e sua crescente industrialização, permite avaliar que esse processo agrega informações de interesse social presente no cotidiano. $O$ processo para disponibilizar a água subterrânea como bem mineral a ser industrializado, passa por etapas de pesquisa, lavra até o teste final com análises de laboratório para classificação da água. Qual a importância da qualidade da água mineral para o consumo humano na promoção de saúde? Para responder esses questionamentos, foi realizada pesquisa bibliográfica, consulta às legislações pertinentes, livros, sites de órgãos públicos. Os resultados demonstraram que a mineração de água mineral é uma atividade presente no cotidiano da sociedade e seu consumo regular contribui para a qualidade e promoção de vida saudável, por meio de controle da exploração de minas de águas minerais, sob gestão da Agência Nacional de Mineração - ANM. Evidenciou-se como a água mineral traz importantes benefícios a saúde: na termorregulação corporal, absorção do calor, transporte de nutrientes, oxigênio, hormônios, composição do plasma sanguíneo, do suco digestivo, formação de saliva, lágrimas, urina. Sendo composta de diferentes níveis de micronutrientes, auxiliam amenizando problemas de saúde, como: enfraquecimento dos ossos e músculos, redução de colágeno, ressecamento da pele, baixa revitalização das células e mucosa, agravados pelo baixo consumo de água com propriedades medicamentosas, produto de uso secular em diversos males que acometem a saúde. Concluiu-se que a prevalência de cada tipo de água mineral e sua composição, desde as ferruginosas, sulfurosas, radioativas, magnesianas e iodetadas, podem auxiliar em tratamentos terapêuticos.

Palavras-Chave: Mineração. Águas Minerais. Consumo Humano. Código de Mineração.

\footnotetext{
${ }^{1}$ Pós- graduado em auditoria, gestão e experiência ambiental. Graduado em Engenharia de Minas. E-mail: antonio.ribeiro@nm.gov.br
} 


\section{INTRODUÇÃO}

Podemos dizer que as águas minerais são casos particulares de águas subterrâneas, uma vez que essa é a sua origem comum, tendo uma relação direta com o ciclo hidrológico. Ao penetrar no interior do subsolo tanto em ambientes rochosos e/ou solo, por onde passa, pelo tempo de percolação, e a depender da profundidade, as águas se enriquecem em alguns constituintes, determinando sua composição química e físico-química, que lhes dão características (CPRM).

Conforme Feitosa, (2008), o ciclo hidrológico representa o percurso da água desde a atmosfera passando pelas fases de precipitação, infiltração, escoamento subterrâneo, escoamento superficial, evaporação e evapotranspiração. O ciclo se inicia a partir da condensação do vapor d'água na atmosfera formando nuvem que caem como chuva. No solo, parte do volume precipitado é interceptada pelas plantas, enquanto outra parte se infiltra em subsuperfície, promovendo a re-hidratação do solo e a recarga das reservas freáticas. $\mathrm{O}$ excesso não infiltrado gera o escoamento superficial que alimenta os córregos, rios e lagos.

Serra (2009, p. 44) avalia que:

A composição química das rochas, por onde se infiltram as águas subterrâneas, é responsável por sua mineralização. As águas das chuvas penetram no solo e atravessam diversas camadas de rochas até estacionarem. Nesse trajeto por baixo do solo, a água passa por rochas com substâncias minerais, como o carbonato e o sulfato de cálcio, que se diluem na água, enriquecendo-a e adquirindo, assim, propriedades medicinais. Outros fatores importantes são a temperatura e a pressão, que ajudam a determinar características próprias à água. As águas minerais dividem-se em fracas, médias e fortes.

A água mineral pode surgir sob a superfície em locais específicos, em nascentes ou fontes naturais ou surgências, ambientes subterrâneos de minas onde se exige a prospecção para a descoberta de águas minerais estacionárias ou de fontes artificiais de onde são captadas. A água mineral possui uma composição química diferenciada das águas comuns, na medida em que é formada por elementos químicos que determinam a característica de ação medicamentosa (SERRA, 2009).

Gorini (2000), analisa que existem duas teorias que buscam explicar a origem das águas minerais, as quais apresentam controvérsias: a primeira, de origem meteórica, os 
estudiosos consideram essa origem a partir de infiltração das águas das chuvas em locais de grande profundidade; a segunda teoria, considera que as águas minerais são de origem magmática, onde parte das águas minerais são resultantes de fenômenos como o vulcanismo.

A água é regulada pelos estados brasileiros, especialmente as de origem subterrânea, que para serem captadas necessitam de um instrumento de outorga, conforme legislação estadual pertinente. A água mineral é classificada como minério e se encontra submetida à Agência Nacional de Mineração - $\mathrm{ANM}^{2}$, portanto, está sob as regras do Código de Águas Minerais.

O presente estudo tem como finalidade avaliar a pesquisa e lavra na mineração de água mineral, em atendimento ao Código de Mineração e Código da Águas, no controle de exploração de minas de águas minerais; analisar a importância do controle da qualidade da água mineral para a promoção de saúde, em conformidade com às Resoluções Anvisa $\mathrm{RDC} 274 / 2005$ e RDC 275/2005.

O estudo aponta a seguinte questão: Qual a importância da qualidade da água mineral para o consumo humano e promoção de saúde?

Para responder a esse questionamento optou-se por realizar uma pesquisa bibliográfica sobre o tema, com a finalidade de contribuir com informações e hipóteses.

Justifica-se a escolha do tema com base no pressuposto em que o Código de Águas Minerais, Decreto-lei no 7.84I/1945, Decreto-lei $\mathrm{n}^{\mathrm{o}}$ 9.406/,2018, que regulamentou o Decreto-lei nº 227/1967 e Regulamentos Técnicos ANVISA - RDC 274/2005, para envase e RDC 275/2005, para características microbiológicas, trouxeram regulamentações na gestão do aproveitamento comercial das fontes de águas minerais que podem ser remetidos a um contexto único e exclusivo, em se tratando de águas minerais com garantia de qualidade para o consumo humano e promoção de saúde.

A relevância social e acadêmica do estudo e as medidas de proteção de águas subterrâneas e a melhoria do enquadramento de áreas de lavras representando as condições de acesso à água mineral de qualidade para a promoção da saúde da população.

\footnotetext{
${ }^{2}$ A Agência Nacional de Mineração foi criada em 25 de julho de 2017, por meio da Medida Provisória n ${ }^{\circ} 791$. Com sede-fonte em Brasília, o órgão é diretamente relacionado ao Ministério de Minas e Energia, e possui autonomia patrimonial e administrativa.
} 


\section{A POLÍTICA NACIONAL DE RECURSOS HÍDRICOS, A GESTÃO DE ÁGUAS E O CÓDIGO DE MINERAÇÃO}

A utilização das águas industrializadas tem significado importante no contexto da sociedade, considerando que os avanços da comunicação propiciaram maior interação das pessoas, que a cada dia, têm demonstrado maior interesse pelas aquisições de alimentos mais saudáveis e entres estes, encontra-se a água mineral industrializada, pela disponibilização acessível e pela segurança alimentar que o produto apresenta, considerando os avanços tecnológicos na operacionalidade dos processos, cada vez mais automatizados e pelo cumprimento das normatizações vigentes.

Conforme Pitaluga (2006), a água mineral foi o produto que nos últimos trinta anos tem tido um crescimento exponencial no consumo entre os brasileiros, posicionando o Brasil está entre os io maiores países consumidores de água mineral do mundo. Segundo a Associação Brasileira das Indústrias de Refrigerante e de Bebidas Não Alcoólicas ABIR, o consumo per capita do mercado brasileiro de águas minerais, avaliado em 2020, foi de 59,65 \%, com um crescimento de 3,9\% em relação ao ano de 2019.

Figura 1: Consumo per capita brasileiro de águas minerais entre os anos de 2010 a 2019.

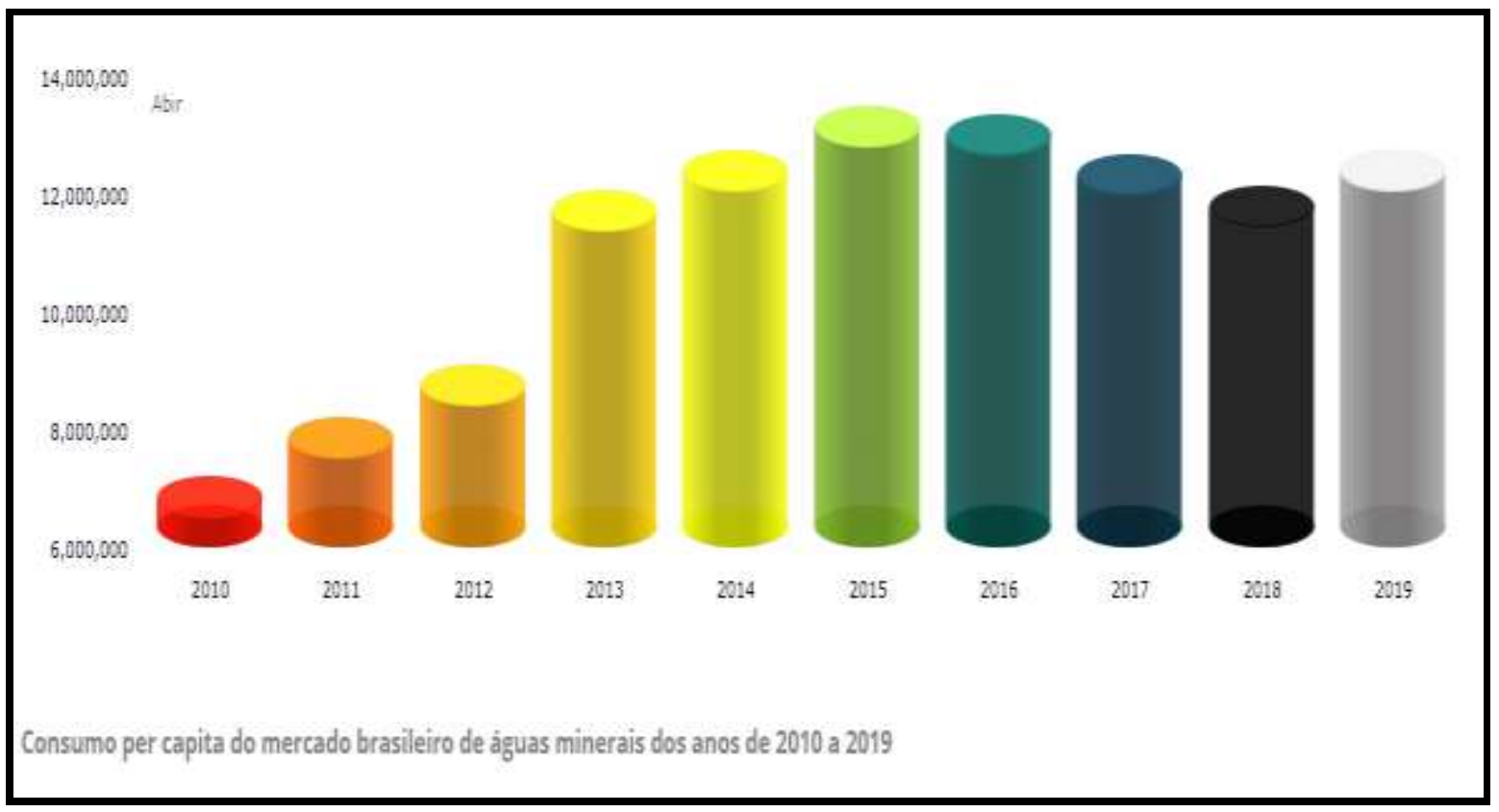

Fonte: Associação Brasileira das Indústrias de Refrigerante e de Bebidas Não Alcoólicas - ABIR (2020). 
Nesse contexto, as comercializações de água mineral se mantêm em destaque e têm um mercado maior que outras categorias de produtos envasados como as bebidas diversas.

A Agência Nacional de Mineração - ANM substituiu o extinto Departamento Nacional de Produção Mineral - DNPM, na gestão e planejamento da exploração mineral e no exercício das atividades de empresas que exploram águas minerais. De modo que a ANM tem a função de regular os interesses de concessão de minas do subsolo.

A União tem com base na exploração de água mineral uma cobrança de royalties, por meio de compensação financeira - CFEM - Compensação Financeira pela Exploração de Recursos Minerais, cujo recolhimento tem como finalidade o repasse para municípios, Estados e União.

O Serviço Geológico do Brasil - CPRM (2021), empresa pública, vinculada ao Ministério de Minas e Energia, tem como atribuição o desenvolvimento de estudo in loco simples que compreendem as coletas de amostras, análises físico-químicas, químicas e bacteriológicas, incluindo as análises dos parâmetros exigidos pela RDC 274/2005.

Ainda conforme a Companhia de Pesquisa e Recursos Minerais - CPRM, as águas minerais para serem classificadas passam por análises de amostras in loco e laboratoriais tanto os componentes químicos como para caracterizar as propriedades físico-químicas inerentes às fontes. As análises são requeridas e avaliadas pela Agência Nacional de Mineração - ANM, em atendimento ao código vigente, capítulo X, art. 38, e realizadas pelos Laboratórios de Análises Minerais - LAMIN do Serviço Geológico do Brasil CPRM, a cada três anos.

A água é regulada pelos estados brasileiros, especialmente as de origem subterrânea, que para captação exige-se instrumento de outorga, conforme legislação estadual pertinente. De mesma origem, subterrânea, a água mineral é classificada como minério e encontra-se submetida à Agência Nacional de Mineração - $\mathrm{ANM}_{3}$, portanto, regulamentada por legislação específica - Código de Águas Minerais - Decreto-lei no $7.841 / 1945$.

\footnotetext{
${ }^{3}$ A Agência Nacional de Mineração foi criada em 25 de julho de 2017, por meio da Medida Provisória no 791. Com sede-fonte em Brasília, o órgão é diretamente relacionado ao Ministério de Minas e Energia, e possui autonomia patrimonial e administrativa.
} 
Conforme Portugal Júnior, Reydon e Portugal (2015, p. I):

Segundo o Código de Mineração, a lavra de água mineral somente deve ser requerida por pessoa jurídica, sendo necessário o requerimento inicial de pesquisa por meio de um projeto cuja área máxima é de so ha. $\mathrm{O}$ alvará de pesquisa terá dois anos de prazo a partir de sua publicação, podendo ser prorrogado por igual período até mais de uma vez, tendo a possibilidade de ser cedido e/ou transferido e, também, renunciado. Após o prazo de pesquisa deve-se apresentar um Relatório Final de Pesquisa.

Os requisitos para lavra de água mineral são necessários e é por meio de seu cumprimento e de outros procedimentos referentes aos regimes de Concessão de Lavra previstos na legislação minerária que a União mantém o controle e a promoção de diretrizes ambientais e operacionais da qualidade da água vigentes. Desta forma, para a obtenção de água mineral é necessário desenvolver pesquisas de prospecção na busca de lavras de água mineral, a partir de Regimes de Autorização de Pesquisa e de Concessão de Lavra, de acordo com as diretrizes do Código de Mineração, bem como o Código de Águas Minerais (ANM).

Figura 2: Pesquisa e prospecção de água mineral com abertura de poços.
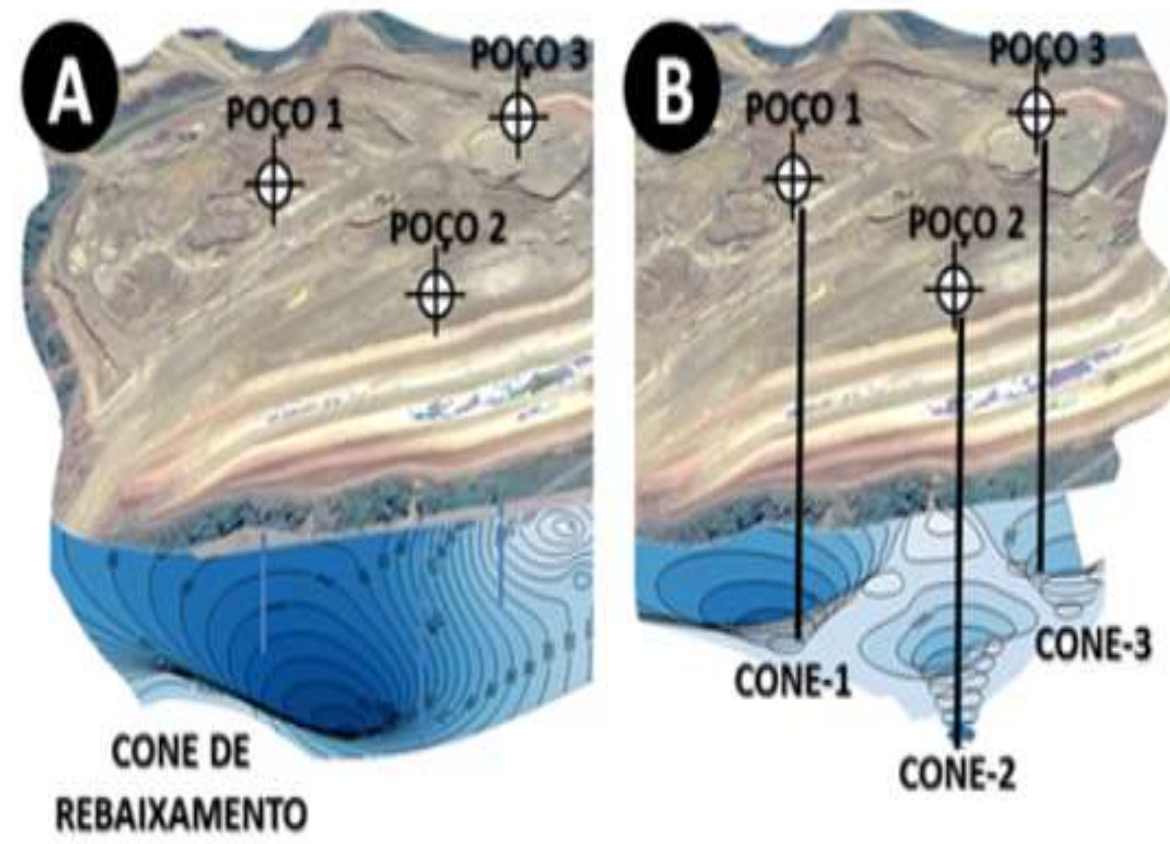

PROFUNDIDADE - NA

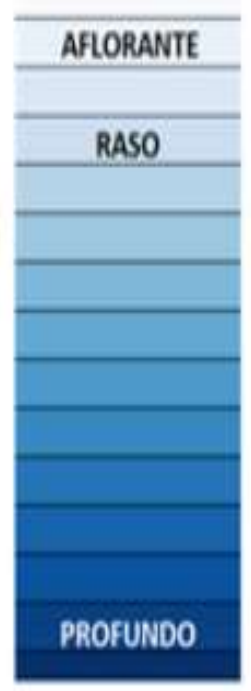

Fonte: Instituto Minere (2020). 
De acordo com Silva (2010), a pesquisa hidrogeológica ganhou destaque no mercado brasileiro, o que representa a realização e prospecção mineral, lavra ou descomissionamento de minas. Esse tipo de pesquisa implica em abertura de poços para a exploração de águas minerais.

Segundo Silva (2010, p. I):

Tal pesquisa engloba uma série de estudos, que envolvem desde a geologia básica dos terrenos até informações e dados mais complexos, como geologia estrutural e geoquímica. Em se tratando dos aspectos físicos das águas subterrâneas, principalmente o sentido e a direção do fluxo hídrico subterrâneo preferencial, leva-se muito em consideração a questão estrutural do terreno (dobras, falhas, fraturas, etc.

Na prospecção de minas é importante definir com precisão o fluxo das águas para fins de alocação de poços, partindo diretamente do centro do alvo para se obter um melhor resultado.

A água mineral é importante na vida do ser humano. Consumida cada vez mais na vida moderna, as empresas têm conseguido celeridade na obtenção das condições técnicas para captação de água para fazer o envasamento e mantém um gerenciamento das áreas de fontes, especialmente por ser um minério expressamente consumido e de fácil contaminação, exige acompanhamento específico dos órgãos reguladores de saúde.

Os autores avaliam não haver conflito entre as regras normativas da União e dos Estados, considerando-se que nem todas as águas subterrâneas são minerais e, portanto, devem atender aos requisitos do Código das Águas Minerais, que assegura a competência e legitimidade de outorga de direito de uso à União.

Conforme Portugal Júnior, Reydon e Portugal (2015, p. I):

A partir de uma nova institucionalidade, concebida dentro de uma abordagem sistêmica dos recursos hídricos no âmbito da bacia hidrográfica à qual pertencem as águas minerais em cada caso, os agentes econômicos deverão apresentar percepções e adotar compromissos e ações que primem por uma exploração sustentável desse recurso, considerando os limites impostos pela capacidade de renovação dada pelas condições dos ciclos hidrogeológicos e os objetivos mais amplos de preservação dessas fontes como reservas hídricas para o futuro. É dentro desse contexto maior que se devem incluir as necessárias análises e considerações com relação ao ciclo de vida, às ações voltadas ao correto destino dos resíduos gerados na produção, na comercialização e no consumo. 
A exploração de água mineral se encontra distribuída de forma irregular na geografia do território e muitas dessas jazidas de águas se encontram em vários estados brasileiros. As concessões de lavra de água mineral ativas são num total de 1.236 concessões de lavras ativas e distribuídas no território brasileiro (ASSIRATI, 20I8).

A Resolução da Diretoria Colegiada - RDC 274/2005, aborda requisitos de ordem sanitária para a água mineral natural que atende a um regulamento técnico específico, de forma a garantir a manutenção das características naturais quando for comercializada. Desta forma, as diretrizes de controle aplicadas pela ANVISA representam garantia de oferta de um produto de qualidade para o consumidor, exigindo das empresas exploradoras de águas minerais, boas práticas de fabricação - BPF, para assegurar que água mineral esteja em perfeitas condições de consumo (ANVISA).

A Resolução 275/2005 da Agência Nacional de Vigilância Sanitária - ANVISA, vinculada ao Ministério da Saúde, traz também a necessidade de análise das condições microbiológicas da água mineral comercializada, as diretrizes determinam a necessidade de ensaios a partir de análises laboratoriais com amostras indicativas ${ }^{4}$ e amostras representativas ${ }^{5}$ do produto.

Quadro I - Características microbiológicas para Água Mineral Natural e Água Natural.

\begin{tabular}{|c|c|c|c|c|c|}
\hline \multirow[b]{2}{*}{ Microrganismo } & \multirow{2}{*}{$\begin{array}{l}\text { Amostra } \\
\text { indicativa } \\
\text { limites }\end{array}$} & \multicolumn{4}{|c|}{ Amostra representativa } \\
\hline & & $\mathrm{n}$ & c & $\mathrm{m}$ & M \\
\hline $\begin{array}{l}\text { Escherichia coli ou colifor-me } \\
\text { (fecais) termotolerantes, em } \\
\text { Ioo } \mathrm{mL}\end{array}$ & Ausência & 5 & o & $-\because$ & Ausência \\
\hline Coliformes totais, em roo $\mathrm{mL}$ & $<\mathrm{I}, \mathrm{o}$ UFC; & 5 & I & $<\mathrm{I}, \mathrm{o}$ UFC; & 2,0 UFC ou 2,2 \\
\hline
\end{tabular}

\footnotetext{
${ }^{4} \mathrm{~A}$ amostra indicada representa Amostra indicativa a amostra que é condenada quando for constatada a presença de Escherichia coli ou coliformes (fecais) termotolerantes ou quando o número de coliformes totais e ou enterococos e ou Pseudomonas aeruginosa e ou clostrídios sulfito redutores ou Clostridium perfringens for maior que o limite estabelecido para amostra indicativa (RESOLUÇÃO 275/2005 - ANVISA).

${ }^{5} \mathrm{~A}$ amostra representativa é obrigatória em cumprimento aos dispositivos legais vigentes. Excetuam-se as atividades que requeiram amostragem para investigação (relacionada com suspeita ou com identificação de problemas na partida, para confirmação ou verificação da sua natureza e extensão ou ainda para informações sobre as possíveis fontes de problema) ou que requeiram inspeções rígidas (planos estatísticos com maior poder de discriminação de falhas) conforme especificado na Resolução275/2005 - ANVISA.
} 


\begin{tabular}{|c|c|c|c|c|c|}
\hline & $\begin{array}{l}<\mathrm{I}, \mathrm{I} \text { NMP } \\
\text { ou } \\
\text { ausência }\end{array}$ & & & $\begin{array}{l}<\mathrm{I}, \mathrm{I} \text { NMP } \\
\text { ou } \\
\text { ausência }\end{array}$ & NMP \\
\hline Enterococos, em roo mL & $\begin{array}{l}<\mathrm{I}, \mathrm{o} \text { UFC; } \\
<\mathrm{I}, \mathrm{I} \text { NMP } \\
\text { ou } \\
\text { ausência }\end{array}$ & 5 & I & $\begin{array}{l}<\mathrm{I}, \mathrm{o} \text { UFC; } \\
<\mathrm{I}, \mathrm{I} \text { NMP } \\
\text { ou } \\
\text { ausência }\end{array}$ & $\begin{array}{l}\text { 2,o UFC ou 2,2 } \\
\text { NMP }\end{array}$ \\
\hline $\begin{array}{l}\text { Pseudomonas aeruginosa, em } \\
\text { Ioo } \mathrm{mL}\end{array}$ & $\begin{array}{l}<\mathrm{I}, \mathrm{o} \text { UFC; } \\
<\mathrm{I}, \mathrm{I} \text { NMP } \\
\text { ou } \\
\text { ausência }\end{array}$ & 5 & I & $\begin{array}{l}<\mathrm{I}, \mathrm{o} \text { UFC; } \\
<\mathrm{I}, \mathrm{I} \text { NMP } \\
\text { ou } \\
\text { ausência }\end{array}$ & $\begin{array}{l}\text { 2,o UFC ou 2,2 } \\
\text { NMP }\end{array}$ \\
\hline $\begin{array}{l}\text { Clostrídios sulfito redutores ou } \\
\text { Clostridium perfringens, em } \\
\text { Ioo } \mathrm{mL}\end{array}$ & $\begin{array}{l}<\mathrm{I}, \mathrm{o} \text { UFC; } \\
<\mathrm{I}, \mathrm{I} \mathrm{NMP} \\
\text { ou } \\
\text { au sência }\end{array}$ & 5 & I & $\begin{array}{l}<\mathrm{I}, \mathrm{o} \text { UFC; } \\
<\mathrm{I}, \mathrm{I} \text { NMP } \\
\text { ou } \\
\text { ausência }\end{array}$ & $\begin{array}{l}\text { 2,o UFC ou 2,2 } \\
\text { NMP }\end{array}$ \\
\hline
\end{tabular}

Fonte: ANVISA (2005).

As empresas que desejam atuar no mercado devem realizar devidamente todas as diretrizes da legislação sanitária para assegurar um consumo sadio, apresentando um projeto de captação de águas que deve passar por vários procedimentos normativos (desde o Requerimento de Pesquisa, Relatório Final de Pesquisa Positivo e Requerimento de Lavra (CAETANO; PEREIRA; DOURADO, 2012).

A União determina por meio do Código de Águas as medidas de proteção às águas subterrâneas quando se trata de comercializar, impondo-se a responsabilidade de manter a qualidade das águas minerais.

$\mathrm{Na}$ última década novos instrumentos de análise da qualidade e da presença de contaminantes tem assegurado a proteção das águas de consumo humano (ESTEVES, 2012).

Em relação à atividade de lavrar, o parâmetro se trata de operações que são ordenadas com o objetivo de aproveitamento industrial do ambiente de lavra, inseridos processos de extração de substâncias minerais, por essa razão todos os agentes privados devem obter a concessão e em relação a água mineral representará a fase durante a execução do aproveitamento sem que exista comprometimento ambiental das características do ambiente de extração da água mineral (COELHO; DUARTE, 2003). 
Nesse aspecto, a ANM é o órgão que tem a competência para determinar mecanismos de regulação, outorga e fiscalização, em relação aos planos de exploração e aproveitamento dos recursos minerais, inclusive a retirada de água mineral do solo ou subsolo, em todo o território nacional. Portanto, a ANM tem a missão de gerir e controlar todas as atividades que envolvem a exploração mineral.

O Código de Águas Minerais - CAM (Decreto-Lei nº 7.841/1945) determina a competência da ANM que atualmente é a representante das obrigações e dos direitos que antes pertencia ao extinto Departamento Nacional de Produção Mineral - DNPM, de acordo com a Lei no 13.575/2017, o processo de fiscalização da exploração das águas minerais e potáveis para uso de mesa em todos os seus aspectos devem ser resultantes de acordo com o art. 9 e 23 :

Art. 9. Por lavra de uma fonte de água mineral, termal, gasosa, potável de mesa ou destinada a fins balneários, entendem-se todos os trabalhos e atividades de captação, condução, distribuição e aproveitamento das águas. (...)

Art. 23. A fiscalização da exploração, em todos os seus aspectos, de águas minerais, termais, gasosas e potáveis de mesa, engarrafadas ou destinadas a fins balneários, será exercida pela Agência Nacional de Mineração ANM.

Art. 24. As autoridades sanitárias e administrativas federais, estaduais e municipais, deverão auxiliar e assistir a ANM em tudo que for necessário ao fiel cumprimento desta lei (BRASIL, 2017, p. I).

A criação da Agência Nacional de Mineração se constituiu no novo marco da mineração, e somente depois foram instituídas as medidas provisórias $n^{\circ}$ 789, 790 e 791 de 2017, que teve como foco seguir as diretrizes constitucionais. Esse novo momento de reavaliação e do aperfeiçoamento do marco legal da mineração, define em termos de políticas legislativas, a competência sobre a regulação das águas subterrâneas sob gestão da Agência Nacional de Águas - ANA, enquanto as águas minerais, por serem consideradas como mineral, são gerenciadas pela Agência Nacional de Mineração - ANM (ANM).

No Código de Minas de 1934, foi determinado o direito de tutela privativa da União, portanto, passaram a ser responsabilidade da esfera federal, saindo da gestão estadual. Somente a partir do Decreto 78.171/1976, os órgãos de saúde passaram a desenvolver um nível maior de controle em termos de análises da qualidade da água mineral (SERRA, 2009). 
Com base no Decreto 78.171/1976 foram criadas diversas outras normativas por meio de portarias dos Ministros de Minas e Energia e da Saúde, com o objetivo de determinar medidas de regulamentação do setor que gerou um controle maior sobre os padrões de qualidade da água mineral (SERRA, 2009).

Depois da criação de novas medidas, começaram a surgir os conflitos entre os órgãos da ANM e as Secretarias de Saúde, os resultados se constituíram em medidas de fiscalização e de regulamentação legal que trouxeram diferenças que geraram conflitos de competência com os órgãos de saúde.

Segundo Caetano, Pereira e Dourado (2012, p. 3):

O controle sanitário da qualidade das águas minerais destinada ao consumo humano, bem como a fiscalização sanitária dos locais e equipamentos relacionados com a comercialização do produto são competências do Ministério da Saúde das Secretarias de Saúde dos Estados e Distrito Federal pelo Decreto no 78.171/1976 (BRASIL, 1976). No entanto, existe um procedimento ainda atuante pelos empresários da indústria de água mineral de atendimento ao Decreto-lei no 4.147/1942. A Portaria 222/1997 do DNPM apresentou conflito com a Portaria 326/1997 do Ministério da Saúde (BRASIL, 1997), pois ambos estabelecem procedimentos para as condições higiênico-sanitárias e exames ambulatoriais e laboratoriais dos funcionários, sendo que essa última é mais detalhada.

Com a Resolução 2I/20 publicada pela ANM, ocorreu a mudança que teve como dinâmica a alteração do regimento interno, trazendo nesse contexto, o detalhamento de atribuições para casos de mediação e conciliação, com a finalidade de acabar com os conflitos de funções. Tais diretrizes foram determinadas no art. $2^{-}$, XIV, da Lei 13.474/2017, para haver o equacionamento de conflitos de natureza territorial entre águas subterrâneas dos Estados geridas pela ANA e as águas minerais administradas pela ANM e outros direitos minerários (ANM)

Serra (2009) avalia que a água é um recurso primordial para a vida na terra. A qualidade da água para o consumo humano representa um fator da maior relevância, na medida em que a água de qualidade promove a saúde.

Conforme Esteves (2012), a água mineral deve atender aos padrões de potabilidade conforme regulamentos da Anvisa, já que, não sendo perfeitamente atendidos, pode se tornar um veículo de transmissão de doenças através de agentes infecciosos. Considerando 
ser a água um alimento e de ingestão presente no dia a dia de todo ser humano, uma água de má qualidade disponibilizada, pode trazer grandes malefícios a uma comunidade.

Esteves (2012, p. 25) analisa que:

A água é necessária à vida e todas as manifestações de vida devem ser compreendidas como reciprocas, nada podendo ser analisado senão dentro de uma visão holística deste todo complexo que é a realidade. O conjunto de normas jurídicas que visa disciplinar a água mineral é um elemento da organização social e não um conjunto estático de normas em aplicação da doutrina puramente positivista.

Nesse contexto, todos os elementos químicos presentes na água devem ter as concentrações adequadas e a qualidade representada pela ausência de contaminantes que podem causar doenças como a verminoses, febre tifoide, a cólera e outras doenças infecciosas.

Existe por parte dos órgãos de saúde e de proteção e gestão de águas o cuidado para evitar a contaminação das águas subterrâneas, destinadas ao consumo da população, incorporando à gestão de águas na esfera estadual uma responsabilidade socioambiental (SERRA, 2009).

A água sendo considerada como um mineral, se constitui em gestão federal que demonstra diferentes políticas e critérios que geram conflitos de resoluções complexas em relação às gestões municipais, estaduais e federais, na medida em que se trata de interesses econômicos de empresas e de consumidores, bem como os representantes que precisam tomar decisões (VAITSMAN; VAITSMAN, 2015).

\section{OS BENEFÍ́CIOS DA ÁGUA MINERAL PARA A SAÚDE}

O processo para tornar a água subterrânea um recurso disponível a ser industrializado, requer etapas de pesquisa, lavra e tratos laboratoriais na determinação da capacidade de atendimento quantitativo à indústria, bem como às condições de assepsia e controle microbiológico para garantir qualidade assegurada ao consumo humano, condição necessária e importante como vetor de promoção de saúde.

A água mineral beneficia o corpo e seus órgãos, especialmente o sistema renal, que tem a função de filtrar e aproveitar os elementos importantes, eliminando o que o organismo não absorve, a partir do sistema urinário. Desta forma, a água quando faz o 
transporte de nutrientes, também tem a função de manter um processo de termorregulação, que representa estabilidade dos níveis de temperatura corporal (VAISTMAN; VAISTMAN, 2015).

A água mineral traz grandes vantagens terapêuticas na medida em que possui nutrientes essenciais à saúde do organismo, como sais minerais, cálcio, flúor e magnésio sem ser submetida a processo químico, portanto, por ser pura, não necessita de nenhuma intervenção humana em sua composição. Sob esse aspecto, existem grandes diferenças entre ingerir água mineral e água tratada, considerando-se que a água mineral natural tem sido reconhecida como medicinal por auxiliar no bom funcionamento dos sistemas do organismo (VAISTMAN; VAISTMAN, 2015).

Em relação às pessoas que ultrapassam os 60 anos, existem uma perda da capacidade de termorregulação da temperatura corporal, representadas pela sensação de sede, calor ou frio. Portanto, nessa faixa etária, as pessoas ficam mais propensas à desidratação. Conforme a Sociedade Brasileira de Alimentação de Nutrição - SBAN, as necessidades de água nos idosos não são diferentes daquelas para os adultos jovens. Entretanto, existe uma série de condições, tanto fisiológicas quanto mórbidas, que alteram o balanço hídrico nesta população específica, colocando-os sob maior risco em relação a estados de desidratação.

Figura 3: Cuidados contra a desidratação.

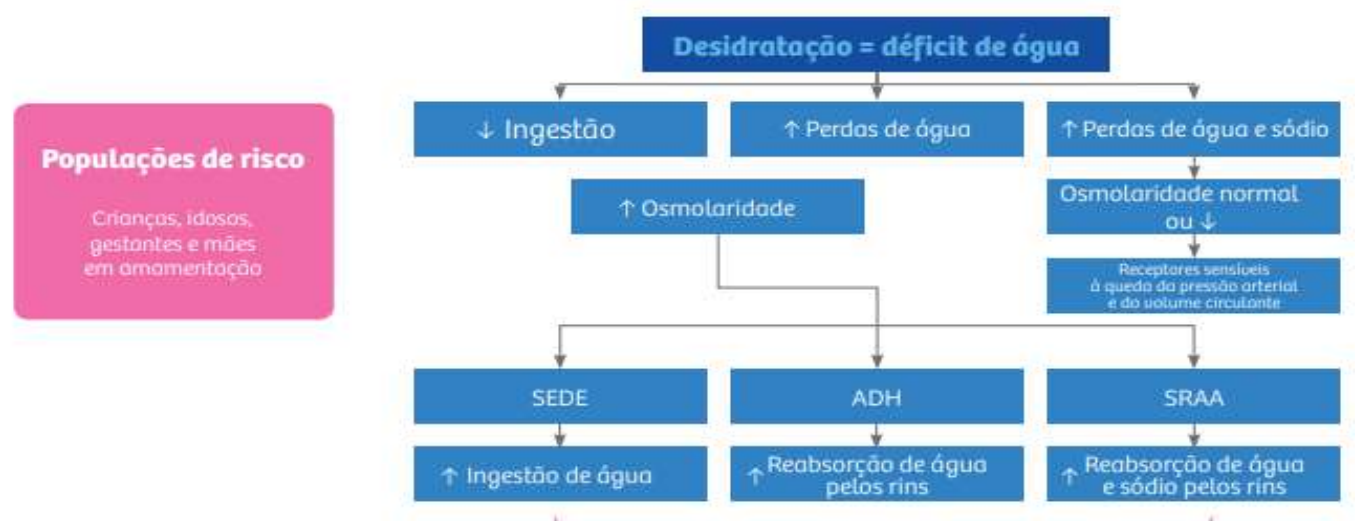

Recuperaçāo do déficit de água

Fonte: Azevedo, Pereira e Paiva (2019). 
Os cuidados com a desidratação também devem ser parte da vida de crianças e gestantes, que devem manter a ingestão satisfatória de água mineral, de forma a manter equilibrada a função diurética. Como a água mineral tem propriedades medicamentosas e terapêuticas em sua composição determinadas pelo tipo de rocha por onde passa, pelo tempo de permanência e temperatura do aquífero, podem apresentar variadas composições, com predominância de certos elementos químicos característicos, a exemplo das águas minerais com maior predominância de elementos ferruginosos, que tem indicação terapêutica para problemas de anemia, alergias e tratamento de parasitoses. Já, a água mineral alcalina-bicarbonatada, tem a função de melhorar o funcionamento gástrico, hepático e pancreático (KUHNE, 2010).

A água mineral sulfurosa, com predominância do elemento enxofre, tem auxiliado pessoas com problemas reumáticos e outras variedades de infecções e dermatites. Ainda existem as águas minerais que possuem em sua composição elementos radioativos, também importantes em atividades terapêuticas, especialmente nos tratamentos em pacientes com problemas renais, possibilitando a melhoria do funcionamento digestivo.

As águas minerais magnesianas têm função laxante e, portanto, geram a regulação do intestino e o funcionamento do estômago, as que apresentam propriedades carbônicas apresentam funções hidratantes para a pele. As águas iodetadas apresentam funções terapêuticas em situações orgânicas inflamatórias, insuficiência da glândula tireoide, e problemas de reumatismo, fígado e rins. Já as águas minerais litinadas tem grande importância no processo de depuração do ácido úrico e possui função calmante (KUHNE, 2010).

As águas minerais ricas em cálcio têm grandes propriedades terapêuticas para o fortalecimento dos ossos, na doença osteoporose e na melhoria das condições musculares e as que apresentam uma concentração elevada de potássio apresentam condições de manter a tonificação do sistema nervoso central (KUHNE, 20Io).

O grande benefício à saúde do consumo de água mineral é inquestionável, considerando a sua efetividade na contribuição à nutrição e à saúde do organismo.

Conforme Azevedo, Pereira e Paiva (2019, p. II): 
A água pode contribuir para a ingestão de alguns micronutrientes, entretanto, no Brasil, grande parte das águas minerais engarrafadas ou de torneira não são consideradas fontes importantes para esses minerais. A classificação europeia das águas minerais descreve que águas ricas em sódio contém > $200 \mathrm{mg} / \mathrm{L}$, em cálcio > $150 \mathrm{mg} / \mathrm{L}$, em bicarbonato > 600 $\mathrm{mg} / \mathrm{L}$, em magnésio > $50 \mathrm{mg} / \mathrm{L}$ e flúor > $\mathrm{mg} / \mathrm{L}$. Não há referências para o potássio, pois em geral não é representativo nas águas.

As águas minerais são ricas em minerais, sais e elementos que fortalecem o organismo. A classificação europeia de águas minerais demonstra os níveis de presença de micronutrientes importantes para promoção da saúde.

O corpo humano para estar saudável deve se manter hidratado, considerando que o sistema urinário do qual faz parte os rins, possuem cerca de $83 \%$ de água, assim como o sistema cardiovascular, os pulmões e o sistema sanguíneo, tem em torno de $80 \%$. Portanto, o organismo necessita estar perfeitamente hidratado para manter as funções digestivas e a nutrição das células, além da importância da água na função de lubrificação da visão e sistema ósseo, do funcionamento do sistema nervoso e no equilíbrio da temperatura corporal (KUHNE, 2010).

Segundo Azevedo, Pereira e Paiva (2019, p. 8):

As necessidades de água nos idosos não são diferentes daquelas para os adultos jovens. Entretanto, existe uma série de condições, tanto fisiológicas quanto mórbidas, que alteram o balanço hídrico nesta população específica, colocando-os sob maior risco em relação a estados de desidratação. As crianças apresentam diferenças fisiológicas importantes em comparação aos adultos, como sua maior área de superfície em relação a massa corpórea, a menor habilidade para produzir suor e um maior metabolismo da água.

Nesse aspecto, o corpo humano dependendo das atividades realizadas, da idade, da altura e do peso corporal necessitam de uma maior ou menor ingestão de água. Considerando as variáveis supracitadas, a ingestão de água pelo ser humano deve ser suficiente para a reposição das necessidades do organismo.

\section{CONSIDERAÇÕES FINAIS}

O presente trabalho possibilitou um questionamento importante. Qual a importância da qualidade da água mineral para o consumo humano e promoção de saúde?

Contempla o questionamento, a partir da pesquisa e resultados que apontaram que para garantir a qualidade da água para o consumo humano e qualidade de vida, a 
obediência às legislações reguladoras e o acompanhamento técnico na indústria desde o envase e controle microbiológico, possibilitam garantia de qualidade final da água mineral, para ser disponibilizada no aproveitamento comercial das fontes de águas minerais como alimento seguro para o consumo humano.

Tais aspectos referentes à mineração de água mineral, para a qualidade do consumo humano e promoção de saúde, evidenciaram que as diretrizes desde a pesquisa, a lavra e beneficiamento, ou seja, industrialização, a partir do ano de 1976, passou a ter um controle mais rígido da qualidade da água por meio dos órgãos responsáveis por garantir proteção aos consumidores.

Evidenciou-se que a água mineral traz grandes benefícios para a saúde, onde os diferentes níveis de nutrientes existentes auxiliam nos mais diversos problemas de saúde, na medida em que suas propriedades medicamentosas são recomendadas em tratamentos de diversos males que acometem à saúde humana. Devido a presença de grande variedade de sais minerais e elementos químicos naturais na composição das águas minerais, estas, apresentam características benéficas nos tratamentos de doenças, considerando a prevalência de cada tipo de água mineral, que caracterizam-na em: ferruginosas, alcalinabicarbonatadas, sulfurosas, radioativas, magnesianas e iodetadas, podem auxiliar em atividades terapêuticas em tratamentos medicinais em pacientes.

Em termos de saúde pública, existem vários problemas no organismo que podem ser tratados com águas minerais ricas em elementos prevalentes que dão características específicas às águas, onde essas propriedades terapêuticas proporcionam benefícios à saúde a partir do consumo regular de água mineral, bem como outros usos como terapias balneoterápicas, etc.

A água mineral entrou na aceitação popular como um produto presente no dia a dia e passou a ser consumido frequentemente por ser seguro e benéfico à saúde, e segundo a Associação Brasileira das Indústrias de Refrigerante e de Bebidas Não Alcoólicas ABIR, o consumo per capita do mercado brasileiro de águas minerais avaliado em 2020, foi superior ao ano de 2019 em mais de $59 \%$, com um crescimento de 3,9\%.

Com a Resolução no 21/2020, da ANM, alterou o Regimento Interno da Agência Nacional de Mineração, reorganizou a estrutura da Autarquia e deslocou unidades 
organizacionais entre a Diretoria Colegiada e as Superintendências. A partir desta Resolução e a previsão de criação da Assessoria de Resolução de Conflitos, órgão de assistência direta e imediata à Diretoria Colegiada, conflitos que dificultam a implantação de novos empreendimentos poderão ser resolvidos de forma célere com benefícios às partes envolvidas e a sociedade do local de implantação do empreendimento.

As diretrizes legislativas obedecem as orientações do Código de Mineração e Código de águas e com as novas resoluções de 2017, que instituiu a Agência Nacional de Mineração - ANM e a extinção do Departamento Nacional de Produção Mineral DNPM, tornaram-se um mecanismo eficiente e célere na solução de problemas minerários.

As águas minerais são controladas pela administração federal, através da ANM no acompanhamento das atividades de extração da água mineral. As diretrizes atuais facilitaram a tramitação do processo de exploração de minas, proporcionando o aumento da produção e do consumo de água mineral pela população, mediante a confiança do controle eficiente da qualidade da água disponível, através de atendimento aos regulamentos da Anvisa e das legislações da ANM.

\section{REFERÊNCIAS}

ABIR - Associação Brasileira das Indústrias de Refrigerante e de Bebidas Não Alcoólicas. Águas minerais. 2020. Disponível em: <https://abir.org.br/o-setor/dados/aguasminerais/>. Acesso em: I8 abr. 202I.

ANM - Agência Nacional de Mineração. Sumário Mineral. DALLA COSTA, Marina Marques; MEDEIROS, Karina Andrade; LIMA, Thiers Muniz (Coord.). Brasília: ANM, 2019.

ANM - Agência Nacional de Mineração. 05/2018. Processos Minerários (Água Mineral). Sistema de Informações Geográficas da Mineração (SIGMINE).

ANVISA - Agência Nacional de Vigilância Sanitária. Ministério da Saúde. Resolução RDC $\mathrm{n}^{\mathrm{o}} 275$ de 22 de Setembro de 2005. Disponível 
em: http://bvsms.saude.gov.br/bvs/saudelegis/anvisa/2005/rdc0275_22_09_2005.html\#: : :te $\mathrm{xt}=\mathrm{A} \% 20 \% \mathrm{C}_{3} \% 8$ Igua\%20Mineral\%20Natural\%20e,Mineral\%20Natural\%20e\%20\% $3 \% 8$ ig ua\%20Natural. Acesso em: 23 abr. 2021.

BRASIL. Lei no 13.575, de 26 de Dezembro de 2017. Disponível em: <www.planalto.gov.br/ccivil_03/_ato2015-2018/2017/lei/l13575.htm>. Acesso em: 04 abr. 202I.

CAETANO, Lúcio Carramilho; PEREIRA, Sueli Yoshinaga; DOURADO, Francisco. Os conflitos do gerenciamento da água mineral no Brasil: Estudo de caso no Estado do Rio de Janeiro. Revista Holos Environment, v. 12, n. 2, pp. 132, 2012.

COELHO, Virgília M. T; DUARTE, Uriel. Perímetros de proteção para fontes naturais de águas minerais. Revista Águas Subterrâneas, n. 17, maio 2003.

CPRM - Companhia de Pesquisa e Recursos Minerais. Águas minerais. 2020. Disponível em: 〈https://aguamineral.cprm.gov.br/geo_meio_ambiente.html〉. Acesso em: I8 dez. 202I.

DNPM - Departamento Nacional da Produção Mineral. 2015. O passo a passo para explorar água mineral. DNPM (última modificação 24/3/2015). Disponível em: <http://www.anm.gov.br/assuntos/aopublico/paginas/explorar-agua-mineral-veja-comoe-facil>. Acesso em: I4 dez. 2021.

ESTEVES, Cristina Campos. Regime jurídico das águas minerais na Constituição de $\mathbf{1 9 8 8 .}$ 2012. 274 f. Tese (Doutorado em Geociências) - Universidade Estadual de Campinas UNICAMP, Campinas, SP, 2012.

Feitosa, Fernando A. C. Hidrogeologia: conceitos e aplicações / organização e coordenação científica / Fernando A. C. Feitosa... (et. al.) ... 3. ed. rev. amp. - Rio de Janeiro : CPRM ; LABHID, 2008. 812 p. 
GORINI, Ana Paula Fontenelle. Mercado de água (envasada) no Brasil e no mundo. Rio de Janeiro: BNDES Setorial, 2000.

INSTITUTO Minere. Águas subterrâneas. Disponível em: $\langle$ https://institutominere.com.br/blog/misteriosos-caminhos-das-aguas-subterraneas〉. Acesso em: 03 abr. 202I.

Karmann, I. 20oı. Ciclo da Água, Água Subterrânea e sua Ação Geológica. In: Teixeira W, Toledo M.G.M, Fairchild T.R., Taioli F. (orgs.). Decifrando a Terra. São Paulo, Oficina de Textos, I늘 ed, 568p. ISBN: 9788504014396

KUHNE, Louis. Cura pela água. I. ed. São Paulo: Hemus, 2010.

Pitaluga, C. M. Fatores que Influenciam o Consumo de Água Mineral. Disponível em: https://repositorio.ufms.br/handle/I23456789/863. Acesso em: I7 dez. 2021.

PORTUGAL JÚNIOR, Pedro dos Santos; REYDON, Bastiaan Philip; PORTUGAL, Nilton dos Santos. As águas minerais no Brasil: Uma análise do mercado e da institucionalidade para uma gestão integrada e sustentável. Revista Ambiente \& Água On Line, v. Io, n. 2, Taubaté/SP, jun. 2015.

SERRA, Sílvia Helena. Águas minerais do Brasil. ı. ed. São Paulo: Millenium, 2009.

SILVA, Marcus Vinícius Andrade. Os misteriosos caminhos das águas subterrâneas. 2010. Disponível em: 〈https://institutominere.com.br/blog/misteriosos-caminhos-das-aguassubterraneas $>$. Acesso em: I8 de mai. de 2021.

VAITSMAN, Delmo Santiago; VAITSMAN, Mauro Santiago. Água mineral. 3. ed. São Paulo: Interciência, 2015. 